\title{
QUEEN'S
UNIVERSITY
BELFAST
}

\section{A new method for estimating liquidity risk: Insights from a liquidity- adjusted CAPM framework}

Papavassiliou, V. G. (2013). A new method for estimating liquidity risk: Insights from a liquidity-adjusted CAPM framework. Journal of International Financial Markets Institutions and Money, 24, 184-197.

https://doi.org/10.1016/j.intfin.2012.12.003

Published in:

Journal of International Financial Markets Institutions and Money

Document Version:

Peer reviewed version

Queen's University Belfast - Research Portal:

Link to publication record in Queen's University Belfast Research Portal

\section{Publisher rights}

This is the author's version of a work that was accepted for publication in Journal of International Financial Markets, Institutions and Money. Changes resulting from the publishing process, such as peer review, editing, corrections, structural formatting, and other quality control mechanisms may not be reflected in this document. Changes may have been made to this work since it was submitted for publication. A definitive version was subsequently published in Journal of International Financial Markets, Institutions and Money, Vol. 24, 04/2013

\section{General rights}

Copyright for the publications made accessible via the Queen's University Belfast Research Portal is retained by the author(s) and / or other copyright owners and it is a condition of accessing these publications that users recognise and abide by the legal requirements associated with these rights.

Take down policy

The Research Portal is Queen's institutional repository that provides access to Queen's research output. Every effort has been made to ensure that content in the Research Portal does not infringe any person's rights, or applicable UK laws. If you discover content in the Research Portal that you believe breaches copyright or violates any law, please contact openaccess@qub.ac.uk. 


\section{Accepted Manuscript}

Title: A new method for estimating liquidity risk: insights from a liquidity-adjusted CAPM framework

Authors: Vassilios G. Papavassilioua

PII: $\quad$ S1042-4431(12)00120-5

DOI: $\quad$ doi:10.1016/j.intfin.2012.12.003

Reference: $\quad$ INTFIN 572

To appear in: $\quad$ Int. Fin. Markets, Inst. and Money

Received date: $\quad$ 22-6-2012

Revised date: $\quad 8-12-2012$

Accepted date: $\quad$ 13-12-2012

Please cite this article as: Papavassilioua, V.G., A new method for estimating liquidity risk: insights from a liquidity-adjusted CAPM framework, Journal of International Financial Markets, Institutions \& Money (2010), doi:10.1016/j.intfin.2012.12.003

This is a PDF file of an unedited manuscript that has been accepted for publication. As a service to our customers we are providing this early version of the manuscript. The manuscript will undergo copyediting, typesetting, and review of the resulting proof before it is published in its final form. Please note that during the production process errors may be discovered which could affect the content, and all legal disclaimers that apply to the journal pertain. 
- We propose a new non-parametric method for estimating stock liquidity betas

- We provide evidence that liquidity risk is a factor priced in the Greek market

- The level of liquidity seems to be an irrelevant variable in asset pricing 


\title{
A new method for estimating liquidity risk: insights from a liquidity-adjusted CAPM framework
}

\author{
Vassilios G. Papavassiliou ${ }^{\text {a }}$
}

a Queen's University Management School, Queen's University Belfast, Riddel Hall, 185 Stranmillis Road, Belfast, Northern Ireland, UK, BT9 5EE E-mail: vpapavassiliou01@qub.ac.uk

Tel: +44(0) 2890974200

Fax: +44(0) 2890974201

\section{Present Address:}

Athens University of Economics and Business, Department of Management Science and Technology, 47A Evelpidon \& 33 Lefkados, 104 34, Athens, Greece E-mail: vpapavass@ aueb.gr

Tel: +302108203670 Fax: +302108828 078

$\dagger$ This paper draws upon my Ph.D thesis at the Queen's University of Belfast. I am grateful to Michael Moore, Peter Dunne, Donal McKillop and Liam Gallagher for insightful comments and suggestions 


\title{
A new method for estimating liquidity risk: insights from a liquidity-adjusted CAPM framework
}

\begin{abstract}
This paper proposes a new non-parametric method for estimating model-free, timevarying liquidity betas which builds on realized covariance and volatility theory. Working under a liquidity-adjusted CAPM framework we provide evidence that liquidity risk is a factor priced in the Greek stock market, mainly arising from the covariation of individual liquidity with local market liquidity, however, the level of liquidity seems to be an irrelevant variable in asset pricing. Our findings provide support to the notion that liquidity shocks transmitted across securities can cause market-wide effects and can have important implications for portfolio diversification strategies.
\end{abstract}

Keywords: Model-free liquidity betas; Liquidity-adjusted CAPM; High-frequency data; Realized betas 


\section{Introduction}

Liquidity is important since its level and variability have implications for portfolio diversification strategies and investment performance. Asset prices are not only affected by systematic risk, as measured by the standard market beta, but also by liquidity risk. Liquidity risk can be defined as the type of risk associated with the inability to buy or sell assets at the market price at the desired time. Liquidity affects asset returns as a characteristic (Amihud and Mendelson, 1986; Brennan and Subrahmanyam, 1996; Amihud, 2002) or as a risk factor (Pastor and Stambaugh, 2003; Acharya and Pedersen, 2005; Martinez et al., 2005; Sadka, 2006; Liu, 2006; Watanabe and Watanabe, 2008). Therefore, liquidity appears to be a proper candidate for a priced state variable.

The studies by Acharya and Pedersen (2005) and Pastor and Stambaugh (2003) suggest that liquidity risk is a factor priced in the market. Besides the evidence from the US market, insights about the importance of liquidity as a risk factor in other developed markets are limited (Liang and Wei, 2012; Lee, 2011). Also, research on emerging markets where liquidity effects may be particularly strong, is almost absent (notable examples are the studies by Bekaert et al., 2007 who analyze daily and monthly data on 19 emerging equity markets, and Rouwenhorst, 1999 who studies the cross-sectional relation between asset returns and liquidity measured by turnover in 20 emerging markets). With the exception of Acharya and Pedersen's (2005) seminal study and Lee's (2011) more recent work, the vast majority of previous studies do not deal with multiple forms of liquidity risk and their effect on asset prices.

The aim of the present study is twofold. In particular, as a first step, a new method for estimating model-free liquidity betas from a recent and detailed high-frequency 
data set is proposed which builds on realized covariance and volatility theory. The main difficulty in testing the risk-return relation is that both the conditional expected return and the conditional variance of the market are not directly observable. To deal with this problem, many studies rely on parametric and semi-parametric procedures (ARCH or stochastic volatility models) to model the conditional mean and variance. In the present study the ex-post return variability is measured by using a nonparametric estimator, namely quadratic variation or integrated variance, that is unbiased for the conditional variance and also unaffected by any specific assumptions about the stochastic process generating returns. The integrated variance is latent, but it can be estimated in a consistent manner using the realized variance.

Using this non-parametric approach, the measurement error that arises as a result of employing a proxy for the latent conditional variance in estimating the risk-return relation is mitigated, thanks to the use of high-frequency data ${ }^{1}$. Since liquidity betas are estimated as a time-varying process without any specific assumptions about the dynamics of their determination, their temporal dimension allows to assess how sensitivity to liquidity risk varies over time. Therefore, within this setting the estimation of liquidity betas becomes more efficient compared to standard methods utilizing liquidity measures derived from lower frequency data sets, as in Acharya and Pedersen $(2005)^{2}$. Also, the estimation of conditional liquidity betas is more realistic than their unconditional version estimated by Acharya and Pedersen (2005), who

\footnotetext{
${ }^{1}$ Even the use of high-frequency data can deviate from $100 \%$ efficiency. Andersen et al. (2005) comment: "The consistency of the realized volatility for the true (latent) integrated volatility relies on the assumption of an ever increasing number of finer sampled high-frequency returns which approach zero. However, in empirical applications market microstructure frictions impose a limit on the number of return observations per unit time interval that can be productively employed. Therefore, realized volatility is subject to a finite-sample measurement error vis-à-vis the integrated volatility"

${ }^{2}$ It is common knowledge in the literature that measures of liquidity calculated from daily data are more coarse and less accurate than liquidity measures derived from microstructure data (see Amihud, 2002).
} 
assume that conditional covariances of innovations in liquidity and returns are constant.

Second, we analyze for the first time in the literature whether the Greek highfrequency stock returns are associated cross-sectionally with betas estimated relative to various liquidity risk factors. That is, we ask whether liquidity risk is priced and whether it can play a significant role in asset pricing. Along these lines, we also provide fresh evidence for the relationship between liquidity as a characteristic and asset returns. Both issues are still an open question, especially for small and less liquid markets with several unique features which often exhibit larger variations in their liquidity (Vaihekoski, 2009) ${ }^{3}$.

Our first motivation for researching data from Greece is the generalization of the research findings of larger markets to other smaller ones with different market structures. Since the Athens Exchange is Southeastern Europe's largest exchange, the results of this study may be viewed as a benchmark for other countries in the region. The bulk of the literature on liquidity and liquidity risk is concentrated on US markets, like the NYSE, which is a hybrid market and combines elements from both order-driven and quote-driven market mechanisms. Hybrid markets offer wider bidask spreads to compensate liquidity suppliers for the higher adverse selection (see Hendershott and Moulton, 2011) and this fact affects the magnitude of bid-ask quote midpoints and the resulting high-frequency volatility and liquidity estimates. This study provides an opportunity for interesting comparisons of our results with those from other financial markets.

\footnotetext{
${ }^{3}$ Smaller markets like Greece tend to have lower liquidity than larger markets. During capital market liberalizations and institutional reforms that promote competition, such as those that took place in the Greek capital market during the period 2003-2006, liquidity significantly increases and transaction costs decrease in the form of narrower spreads (Bollen et al., 2004). This is a unique feature of smaller and less liquid markets like Greece which exhibit large liquidity variations especially during periods of liberalization processes.
} 
Our second motivation lies in the fact that high-frequency data are scarce for the majority of markets. Our newly proposed method for estimating liquidity risk would not have materialized if it wasn't for a rich high-frequency database. Finally, we are motivated by the fact that liquidity provision in order-driven markets has received relatively little attention in the microstructure literature compared to quote-driven markets (Glosten, 1994; Handa et al., 1998).

Both papers by Acharya and Pedersen (2005) and Pastor and Stambaugh (2003) use portfolios as test assets in order to estimate the liquidity betas. Contrary to these papers, this study employs individual stocks rather than portfolios in estimating liquidity risk. The use of individual stocks in empirical asset pricing tests helps avoiding spurious results that may arise when characteristic-based portfolios are used as test assets, minimizes the potential loss of information contained in each stock and increases the number of observations for empirical testing (Lee, 2011). Given the central importance of asset pricing in finance, its association with market microstructure can reveal the role played by microstructure factors in influencing the dynamics of asset pricing. We show that liquidity risk is strongly priced in the Greek stock market raising the prospect of a commonality in liquidity effect, however, the level of liquidity seems to be an irrelevant variable in asset pricing.

Our findings have direct policy implications amid periods of perceived market uncertainty occurring during significant financial events, such as the $1987 \mathrm{crash}$, the 1998 collapse of LTCM, and the current European sovereign debt crisis. During periods of large liquidity dry-ups, effects such as "flight-to-quality" or "fligh-toliquidity" are observed, where investors try to rebalance their portfolios toward less risky and more liquid assets. Since the flow of funds between markets affects 
illiquidity, it should also impact asset prices and the risk premium required by investors.

The remainder of the paper is organized as follows: Section 2 briefly illustrates the theoretical framework underlying this study. Section 3 describes the methodology and the data set. Section 4 discusses the estimation results and Section 5 provides some conclusive remarks.

\section{Theory}

The use of realized volatility as a practical benchmark may be justified by standard continuous-time arguments. Following Andersen et al. (2005), we focus on a single asset traded in a liquid financial market and assume that the sample-path of the logarithmic price process, $\left\{p_{t}, 0 \leq t\right\}$, is continuous. The following stochastic differential equation can conveniently express the class of continuous-time volatility models used in finance applications,

$$
d p_{t}=\mu_{t} d t+\sigma_{t} d W_{t}
$$

where $W_{t}$ denotes a standard Brownian motion and the drift term $\mu_{t}$ is predictable and of finite variation. Focusing on the unit time interval, the one-period continuously compounded return for the price process in (1) is given by,

$$
r_{t} \equiv p_{t}-p_{t-1}=\int_{t-1}^{t} \mu_{u} d_{u}+\int_{t-1}^{t} \sigma_{u} d W_{u}
$$

Conditional on the sample-path realizations of the drift and instantaneous volatility processes, the one-period returns are Gaussian with conditional mean equal to 
$\int_{t-1}^{t} \mu_{u} d_{u}$, and conditional variance equal to the unobservable in any direct way integrated volatility,

$$
I V_{t} \equiv \int_{t-1}^{t} \sigma_{u}^{2} d u
$$

which constitutes a natural measure of the ex-post return variability. By the theory of quadratic variation, the corresponding realized volatility defined by the summation of $1 / h$ intra-period squared returns, $R V_{t}(h) \equiv \sum_{i=1}^{1 / h} r_{t-1+i h}^{(h) 2}$, converges uniformly in probability to $I V_{t}$ as $h \rightarrow 0$. Andersen et al. (2001b) show that the quadratic variation and covariation are intimately related to the conditional return variance and covariance. Specifically:

$$
\begin{gathered}
\operatorname{Var}\left(p_{k}(t) / F_{t-h}\right)=E\left[Q \operatorname{var}_{k . h}(t) / F_{t-h}\right] \\
\operatorname{Cov}\left(p_{k}(t), p_{j}(t) / F_{t-h}\right)=E\left[Q \operatorname{cov}_{k j, h}(t) / F_{t-h}\right]
\end{gathered}
$$

where $F_{t}$ denotes the $\sigma$ field that reflects the information at time $t$. The conditional variance and covariance diverge from the quadratic variation and covariation by a zero-mean error. Unlike the conditional variance and covariance which are ex ante concepts, the quadratic variation and covariation are in principle observable via highfrequency returns and can facilitate the estimation of their empirical counterparts, i.e. the $h$-period realized volatility and covariance. Realized volatility and covariance provide unbiased estimators of the conditional variance and covariance without relying on any underlying model (Andersen et al., 2001b; Protter, 2004). This greatly facilitates the estimation of realized betas which are consistent for the true underlying 
integrated beta, as well as the construction of the liquidity betas proposed in this study.

\section{Methodology and the Data}

The Athens Exchange is a developed stock market and the official market for shares in Greece. It is an order-driven market with voluntary market makers participation and provides fully electronic trading and clearing. In pure order-driven markets there are no designated market makers but only brokers who do not take own positions in the assets traded. There is a $15 \%$ of listed firms on the Athens Exchange that have designated market makers, and this distinct feature indicates that the Greek stock market is less ex-post transparent than pure order-driven markets, allowing dealers to offset the risk of excessive inventory positions (Dunne et al., 2011). Trading hours are set between 10:15 GMT+2 and 17:20 GMT+2 for Big Capitalization shares.

The realized volatility approach works most effectively for actively traded stocks which provide reliable high-frequency return observations, thus, our attention is focused on the large capitalization index of the Greek stock market. We employ a sub-sample of the data set used by Dunne et al. (2011). It is based on quotation data of the six most heavily traded and continuously listed blue-chip stocks of the FTSE/ATHEX20 index, for the period extending from September 23, 2003 through March 31, 2006, totaling 635 trading days. These stocks provide a sufficient number of quotations for sampling at a 5-minute frequency and are representative of the Greek stock market. The stocks are: Alpha Bank (ALPHA), National Bank of Greece (ETE), Eurobank (EUROB), Hellenic Telecommunications (HTO), Public Power Corporation (PPC), and Piraeus Bank (TPEIR). All pre-sessional quotations have been excluded, as well as quotations with special settlement conditions which differ 
from normal trades. The FTSE/ATHEX20 index is the large capitalization index capturing the 20 largest blue-chip firms within the Big Cap segment of the Greek stock market. It is a free-float market capitalization weighted index where dividends are taken into account for the calculation of returns ${ }^{4}$.

There were favorable developments that took place in the Greek capital market during the sample period used in this study. To name a few, new products and indices were launched, the number of market makers increased, new informational technology systems were developed, market transparency was promoted and liquidity significantly strengthened, market peculiarities removed, the regulatory framework was modernized, market trading hours were expanded, and the establishment of partnerships with other exchanges in the wider South-Eastern Europe and Mediterranean region was promoted. All the aforementioned developments led to an increased foreign investors' participation in the capitalization of equities forming FTSE/ATHEX20, from 39.43\% in 2003 to $52.31 \%$ in 2006 (Source: Athens Exchange, Monthly Statistics Bulettin \& Annual Reports, available at: www.helex.gr). In periods of lower liquidity, the construction of high-frequency liquidity measures and the implementation of our methodology would have been problematic, as stocks would be thinly traded.

The results of this study are sensitive to the choice of period. Our sample period is a relatively calm volatility period as well as a liquid one. In turbulent and crisis periods there is a widening of liquidity premia and a magnification of liquidity risk resulting in fligh-to-liquidity effects, accompanied by a widening of spreads leading to larger than usual realized volatility estimates (Vagianos, 2004; Allen and Carletti, 2008). On the volatility side, equity market volatility is generally higher during

\footnotetext{
${ }^{4}$ More information can be found in the ATHEX Fact Book available at: http://www.athex.gr.
} 
recessions and crises periods, as the lack of liquidity hinders the price discovery process and causes uncertainty about security values leading to flight-to-quality episodes (Veronesi, 1999; Vagianos, 2004; Parlour and Seppi, 2008). Also, there are concerns about structural breaks that occur around the beginning of periods of stress. Our sample period does not suffer from the aforementioned shortcomings.

It is common practice in the realized variance literature to use midpoints of bid-ask quotes as measures of the true prices, which are generally less noisy measures of the efficient prices than are transaction prices since they do not suffer from bid-ask bounce effects (Bandi and Russell, 2006). The selection of 5-minute returns as the optimal sampling frequency is probably the most popular choice and has been used extensively in the realized volatility literature (Andersen and Bollerslev, 1997, 1998; Andersen et al., 2001a,b). The 5-minute intraday returns are constructed from the linearly interpolated logarithmic midpoint of the continuously recorded bid and ask quotes. That is, we transform our inhomogeneous raw series to homogeneous, regularly spaced series using a technique which is standard practice in the literature (Dacorogna et al., 2001). Similar to Andersen et al. (2001b) we use linear interpolation method to artificially construct equally-spaced intraday 5-minute returns. The continuously compounded 5-minute returns are computed from the log quote-midpoints and are constructed from the logarithmic difference between the midpoints recorded at these appropriately spaced 5-minute intervals, i.e. they are simply the change in these 5-minute average log bid and ask prices. The summation of intradaily squared 5-minute returns gives the daily realized variance measure, while daily realized volatility is obtained using the square-root of the variance series.

Acharya and Pedersen (2005) estimate three liquidity betas representing different forms of liquidity risk by employing the illiquidity measure of Amihud (2002) which 
is constructed from daily data. By assuming constant conditional variance or constant premia, the unconditional version of their model can be expressed as:

$$
E\left(r_{t}^{i}-r_{t}^{f}\right)=E\left(c_{t}^{i}\right)+\lambda \beta^{1 i}+\lambda \beta^{2 i}-\lambda \beta^{3 i}-\lambda \beta^{4 i}
$$

where

$$
\begin{aligned}
\beta^{1 i} & =\frac{\operatorname{cov}\left(r_{t}^{i}, r_{t}^{M}-E_{t-1}\left(r_{t}^{M}\right)\right)}{\operatorname{var}\left(r_{t}^{M}-E_{t-1}\left(r_{t}^{M}\right)-\left[c_{t}^{M}-E_{t-1}\left(c_{t}^{M}\right)\right]\right)} \\
\beta^{2 i} & =\frac{\operatorname{cov}\left(c_{t}^{i}-E_{t-1}\left(c_{t}^{i}\right), c_{t}^{M}-E_{t-1}\left(c_{t}^{M}\right)\right)}{\operatorname{var}\left(r_{t}^{M}-E_{t-1}\left(r_{t}^{M}\right)-\left[c_{t}^{M}-E_{t-1}\left(c_{t}^{M}\right)\right]\right)} \\
\beta^{3 i} & =\frac{\operatorname{cov}\left(r_{t}^{i}, c_{t}^{M}-E_{t-1}\left(c_{t}^{M}\right)\right)}{\operatorname{var}\left(r_{t}^{M}-E_{t-1}\left(r_{t}^{M}\right)-\left[c_{t}^{M}-E_{t-1}\left(c_{t}^{M}\right)\right]\right)} \\
\beta^{4 i}= & \frac{\operatorname{cov}\left(c_{t}^{i}-E_{t-1}\left(c_{t}^{i}\right), r_{t}^{M}-E_{t-1}\left(r_{t}^{M}\right)\right)}{\operatorname{var}\left(r_{t}^{M}-E_{t-1}\left(r_{t}^{M}\right)-\left[c_{t}^{M}-E_{t-1}\left(c_{t}^{M}\right)\right]\right)}
\end{aligned}
$$

and $\lambda=E\left(\lambda_{t}\right)=E\left(r_{t}^{M}-c_{t}^{M}-r^{f}\right)$. The terms $c_{t}^{i}$ and $c_{t}^{M}$ represent the relative illiquidity cost of individual assets and that of the market, respectively. $\beta^{1 i}$ represents the standard market beta, and $\beta^{2 i}, \beta^{3 i}, \beta^{4 i}$ represent the three liquidity betas.

There are two problems with the Amihud daily measure: $(a)$ it is not stationary (see Acharya and Pedersen, 2005) and (b) it does not directly measure the cost of a trade. This study proposes an alternative measure as a proxy for liquidity, the quoted spread. The advantages of this measure are: $(a)$ it is derived from high-frequency data sets $(b)$ it is stationary by nature $(c)$ it directly measures the cost of a trade. The orderbased quoted spread measure $(A s k-B i d)$ is constructed for all six stocks from our clean quotation data set, resulted from the removal of all pre-sessional quotations, quotations with special settlement conditions and negative spreads. The trading day is divided into artificially constructed equally-spaced linearly interpolated 5-minute intervals, and the individual stocks' quoted spread is aggregated in order to obtain an 
aggregate market liquidity measure: $L I Q_{m j t}=\frac{1}{n_{m j t}} \sum_{i=1}^{n_{m i j}} L I Q_{i j t}$ where $L I Q_{i j t}$ is the liquidity measure for stock $i$ on interval $j$ of day $t$, and $n_{m j t}$ is the number of stocks in market $m$ on interval $j$ of day $t$. This technique produces an equally-weighted market spread measure ${ }^{5}$. As a next step, the liquidity innovations in the liquidity proxy are computed for each interval, both at an aggregate market and individual stock level.

Empirically, liquidity is time-varying and persistent (Chordia et al., 2000; Hasbrouck and Seppi, 2001; Huberman and Halka, 2001). Persistence of liquidity implies that liquidity predicts future returns and co-moves with contemporaneous returns (Acharya and Pedersen, 2005). Therefore, there is great necessity in focusing on the innovations in liquidity when computing the liquidity betas. One common method of accounting for serial correlation is to fit an autoregressive model (AR) using certain information criteria. Such a specification is similar in spirit to the autoregressive specification employed by Pastor and Stambaugh (2003) and Acharya and Pedersen (2005). The focus on the innovations in liquidity computed by fitting our data to an autoregressive model, not only alleviates the aforementioned autocorellation problem, but also helps in reducing the measurement error and gives rise to more accurate forecasts and statistically significant lower pricing errors (Bollerslev and Zhang, 2003).

\footnotetext{
${ }^{5}$ Market-wide value-weighted liquidity measures can also be employed. Pastor and Stambaugh (2003) report that value-weighted series tend to underestimate results for periods with low liquidity and high volatility. Moreover, value-weighted series fail to exhibit any flight-to-quality effects. Acharya and Pedersen (2005) argue that equally-weighted averages is a way of compensating for the overrepresentation in their sample of large liquid securities, as compared to the true market portfolio in the economy. Liu (2006) argues that value-weighting tends to underestimate the liquidity premium. This is likely due to some temporarily illiquid larger-cap stocks included in the portfolio. This argument is manifested in our data set, where temporarily illiquid stocks are found. These studies, among many others, have shown that equally-weighted and value-weighted methods lead to very similar results and can be used interchangeably.
} 
We fit our data to an autoregressive model (AR) for the entire sample period, using the Schwarz information criterion (SIC) and employ the residuals obtained from the model as the liquidity innovations, similar to Pastor and Stambaugh (2003) and Acharya and Pedersen (2005). Lee (2011) argues that time-series fitting using the entire sample period includes a look-ahead bias, assuming that future series is known at any point of time. We acknowledge a possible look-ahead bias in the liquidity innovations and construct three different liquidity betas, using the liquidity innovations in the liquidity proxy, following Acharya and Pedersen (2005): the first due to covariation between a security's liquidity and the market liquidity, the second due to covariation between a security's return and the market liquidity, and the third due to covariation between a security's liquidity and the market return:

$$
\begin{gathered}
\beta_{i t}^{2}=\frac{\sum_{j=1}^{N_{t}} L I Q_{i j t} L I Q_{m j t}}{\sum_{j=1}^{N_{t}} r_{m j t}^{2}} \\
\beta_{i t}^{3}=\frac{\sum_{j=1}^{N_{t}} r_{i j t} L I Q_{m j t}}{\sum_{j=1}^{N_{t}} r_{m j t}^{2}} \\
\beta_{i t}^{4}=\frac{\sum_{j=1}^{N_{t}} L I Q_{i j t} r_{m j t}}{\sum_{j=1}^{N_{t}} r_{m j t}^{2}}
\end{gathered}
$$

where $L I Q_{i j t}$ is the spread liquidity innovation of stock $i$ on interval $j$ of day $t, r_{i j t}$ is the return of stock $i$ on interval $j$ of day $t, L I Q_{m j t}$ is the market's liquidity innovation on interval $j$ of day $t, r_{m j t}$ is the return of the FTSE/ATHEX20 index on interval $j$ of day $t$, and $N_{t}$ denotes the number of units into which day $t$ is partitioned. The liquidity-adjusted CAPM posits that $\beta_{i t}^{2}$ should be positively related to expected returns, implying that assets whose liquidity negatively comoves with 
market liquidity are traded at a premium, whereas $\beta_{i t}^{3}$ and $\beta_{i t}^{4}$ should be negatively related to expected returns.

The beta estimates constructed in (11)-(13), are based on Andersen's et al. (2006) realized beta logic, where the realized beta is defined as:

$$
\hat{\beta}_{i t}=\frac{\sum_{j=1}^{N_{t}} r_{i j t} r_{m j t}}{\sum_{j=1}^{N_{t}} r_{m j t}^{2}}
$$

where using similar notation to equations (11)-(13), the numerator denotes the realized covariance between the market and the $i$ th individual stock return, and the denominator denotes the realized market volatility. Based on continuous-record theory, realized market variance and realized covariance are consistent estimators of integrated market volatility and covariance and the realized beta will also be consistent for the true underlying integrated beta (Barndorff-Nielsen and Shephard, 2004). Therefore, our newly proposed non-parametric method of measuring liquidity risk builds on realized covariance and realized volatility theory, and it is empirically implemented using Acharya and Pedersen's (2005) liquidity-adjusted CAPM.

Similar to Acharya and Pedersen (2005), two additional beta measures are defined:

$$
\begin{gathered}
\beta_{i t}^{5}=\beta_{i t}^{2}-\beta_{i t}^{3}-\beta_{i t}^{4} \\
\beta_{i t}^{6}=\beta_{i t}^{1}+\beta_{i t}^{2}-\beta_{i t}^{3}-\beta_{i t}^{4}
\end{gathered}
$$

where $\beta_{i t}^{5}$ constitutes a linear combination of the three liquidity betas excluding market beta and is called the liquidity net beta, which helps differentiate the pricing effect of liquidity risks from that of market risk, whereas $\beta_{i t}^{6}$ contains all four 
covariance terms in it and is called the net beta. $\beta_{i t}^{1}$ denotes the standard market beta and is constructed as in equation (14).

\section{Empirical Results}

\subsection{Statistical Properties}

Table 1 provides a set of summary statistics for the unconditional univariate distribution of daily volatilities. Attention is focused on three volatility measures: variances, standard deviations and logarithmic standard deviations. It is evident from Panel A that the distributions of realized variances are extremely right-skewed and leptokurtic. Also the normality assumption is clearly rejected according to the JarqueBera statistic. Similar results have been noticed in Andersen et al. (2001a) and Ebens (1999) for the US market. Panel B refers to the realized standard deviations. The skewness and kurtosis values are much smaller than before, although the sample kurtosis for all six stocks exceeds the normal value of three. It is clear that transforming the realized variance to realized standard deviation, moves its distribution toward symmetry. Finally, Panel C refers to the raw realized logarithmic standard deviations. The sample kurtosis for all but one of the stocks exceeds the value of three, however, the normality assumption is much better than before, in fact the distributions are now approximately Gaussian.

Table 2 summarizes the conditional distribution of daily realized logarithmic standard deviations. Ljung-Box Q tests show that there is evidence of autocorrelation up to the $22^{\text {nd }}$ order, since the joint null hypothesis that all of the first 22 autocorrelation coefficients are zero is rejected (critical values from a Chi-squared distribution with 22 degrees of freedom are 33.92 at the $5 \%$ level and 40.29 at the $1 \%$ 
level). Clearly, the highly significant Q tests reject the white noise hypothesis for all six stocks. In spite the results from the Q test, the ADF unit root tests displayed in the third column of the table reject the null hypothesis of a unit root, as judged by the $5 \%$ level critical value (-2.86). Therefore, all series are clearly stationary.

The degree of fractional integration $d$ is estimated based on Geweke and PorterHudak (1983) semi-parametric procedure. The estimate of $d$ devised by GPH, relies on the unbounded shape of the spectral density $f(\omega)$ for low frequencies $\omega$ and it is obtained from $n$ observations and $m \ll n$ values of the sample periodogram $I\left(\omega_{j}\right)$ that estimate $f\left(\omega_{j}\right)$ at the frequencies $\omega_{j}=2 \pi j / n, j=1,2, \ldots, m$ (Taylor, 2005). The majority of studies set $m=n^{\theta}$, for a power $\theta$ between 0.5 and 0.8 . Table 2 reports the results for $d$ based on the GPH procedure. OLS standard errors are given in parentheses. Clearly, there is robust evidence of fractional dynamics with long memory features for almost all series which are covariance stationary, as their $d$ estimates lie below the stationary boundary of 0.5 and are statistically significant.

Table 3 depicts summary statistics for the standard daily realized beta estimates constructed using a 5-minute sampling frequency, as described in (14). The daily realized beta estimates have been implemented using the Scholes and Williams (1977) logic. In particular, Scholes and Williams (1977) show that beta estimates are biased downward for securities trading infrequently whereas are biased upward for frequently traded securities. In order to deal with this bias they propose the following consistent beta estimator:

$$
\hat{\beta}=\frac{\beta_{n}^{-}+\beta_{n}+\beta_{n}^{+}}{1+2 \rho}
$$


where $\beta_{n}^{-}, \beta_{n}$ and $\beta_{n}^{+}$are the regression coefficients derived from three separate regressions, in which the return on the security is regressed on lagging, coincident, and leading returns on the market, and $\rho$ is the first-order autocorrelation coefficient of the market return proxy. Following Scholes and Williams (1977) and Andersen's et al. (2004) implementation using high-frequency data, the high-frequency beta estimates consist of the contemporaneously measured beta plus the first-order lag and lead beta obtained from the covariance of the individual 5-minute stock return with the lagged and lead 5-minute market return, divided by the adjusted for serial correlation market return variance estimate. The sample standard deviations suggest that realized betas vary significantly through time. The ADF and Q tests suggest stationarity and mild serial dependence, respectively.

Rows 6 and 8 of Table 3 summarize aspects of the time series dependence structure of daily realized covariances where the existence of important temporal variation is evident. It is shown that the Ljung-Box statistic for the beta series has a lower value than that of covariances, evidencing less serial dependence in the daily realized betas. The results from the GPH estimates suggest that realized betas are integrated of a lower order than are the realized covariances, corresponding to a situation of non-linear fractional integration. An $I(d)$ behaviour with an average $d \in[0,0.15]$ seems to be representative for betas, whereas the realized covariance measures are better approximated as $I(d)$ with $d \in[0,0.33]$. These results are in line with those of Andersen et al. (2006) from the US market.

Panel A of Table 4 shows the liquidity beta estimates constructed from 5-minute individual stock and market returns and individual stock and market liquidity 
innovations ${ }^{6}$. The ADF unit-root tests reported in Panel B of the table provide evidence of stationarity for all liquidity beta estimates.

\subsection{Fama-MacBeth Regressions}

In this section the liquidity-adjusted CAPM is evaluated by applying the Fama and MacBeth (1973) cross-sectional test ${ }^{7}$. The basic idea of Fama-MacBeth is that any variability in standard market betas is significantly related to the cross-sectional variability of stock returns ${ }^{8}$.

Cross-sectional regressions are performed every month using individual stock returns and estimated betas and the time-series average of estimated premia are generated $^{9}$. Standard errors are computed using the Newey and West (1987) method with four lags. The total number of observations in the cross-sectional series is 3,810 . Month-by-month regressions are performed employing roughly 130 observations each. Table 5 summarizes the results of the Fama-MacBeth cross-sectional regressions. Panel A shows that the net beta including market risk is priced in the Greek stock market ( $t$-value of 2.19) but with a low premium. The liquidity net beta which includes only the three liquidity betas is also priced ( $t$-value of 2.19) as depicted in Panel B. We further proceed to isolate the effect of market risk from the

\footnotetext{
${ }^{6}$ The influence of intraday seasonality in the liquidity betas can be removed by standardizing the data following Hasbrouck and Seppi (2001).

${ }^{7}$ The risk-free rate is not taken into account in our empirical model

${ }^{8}$ The Fama-MacBeth methodology has recently been criticized by Asparouhova et al. (2010). As they assert, standard regression-based tests of whether average returns contain a premium for illiquidity are biased towards finding a premium. They report results obtained with the Fama-MacBeth methodology, where return premia are estimated as time series averages of regression coefficients obtained in periodby-period cross-sectional regressions of returns on beta estimates and security characteristics (bid-ask spreads) for a sample of NYSE/AMEX stocks. They show that almost half of the empirical estimate of the return premium is attributable to bias arising from microstructure noise. This bias can be reduced but not completely eliminated by the use of quote midpoints instead of trade prices. We also employ the GMM methodology as a robustness test on whether liquidity risk is priced in the Greek stock market. The GMM estimated results are not dramatically different from those of the Fama-MacBeth methodology and are available by the author upon request.

${ }^{9}$ The liquidity-adjusted CAPM using the net beta as the independent variable in the cross-sectional regressions fares better than the standard CAPM in terms of $R^{2}$, although both models employ one degree of freedom.
} 
net beta's performance in order to measure its dinstict contribution to the pricing of Greek blue-chips. As shown in Panel C of the same table, market risk has the expected sign according to the predictions of the CAPM, however, it is not priced ( $t$ value of 0.27). Such a finding coincides with the results of Fama and French (1992) and others who show that market risks work poorly in explaining cross-sectional differences of asset returns.

By examining each liquidity risk separately (Panel D) we demonstrate that the liquidity net beta is priced solely due to $\beta_{i t}^{2}$, whereas $\beta_{i t}^{3}$ and $\beta_{i t}^{4}$ are not priced. $\beta_{i t}^{2}$ is positive and significant at the $5 \%$ level, indicating a strong presence of commonality in liquidity in the Greek stock market (see Dunne et al., 2011 for further analytical evidence). Hence, it is evident that investors require a return premium for assets that are illiquid when the market as a whole is illiquid. This result is also supported by Acharya and Pedersen (2005), but differs from Lee's (2011) evidence concerning the US and other developed markets. $\beta_{i t}^{3}$ which is derived from a sensitivity of asset return to market liquidity, has a negative sign consistent with the predictions of the liquidity adjusted-CAPM but it is not priced ( $t$-value of -0.35 ). This finding is inconsistent with US evidence of Pastor and Stambaugh (2003) and Bekaert et al. (2007) for emerging markets, however, it is consistent with Lee's (2011)

evidence from the US market and emerging markets. $\beta_{i t}^{4}$ which is derived from the covariance of individual stock liquidity with market returns exhibits a reversed sign (positive) and is not priced at all conventional significance levels, a result inconsistent with Acharya and Pedersen $(2005)^{10}$. The average adjusted $R^{2}$ values are small but

\footnotetext{
${ }^{10}$ The presence of multicollinearity in the model makes it hard to distinguish the separate effects of liquidity risk and may camouflage significance of liquidity as a characteristic. Looking at the matrix of correlations between the explanatory variables, near multicollinearity is not detected since the observed correlations are sufficiently small that can reasonably be ignored.
} 
consistent with earlier studies that report $R^{2}$ for the firm-level cross-sectional regressions (Bali et al., 2009).

Summarizing the results, it can be said that Greek investors are compensated for holding stocks with sensitivity to local market-wide liquidity fluctuations, and that sensitivity is priced mainly due to commonality in liquidity effect. The difference in the magnitude and nature of our results with those of Acharya and Pedersen (2005) could be due to the fact that they employ a different measure of liquidity, or due to the fact that they use portfolios of stocks sorted based on the level of liquidity or liquidity risk, whereas the present study employs individual stocks. In Table 6 the extended Fama-MacBeth cross-sectional regressions are considered, where $E\left(c_{t}\right)$ denotes the expected liquidity computed as each stock's average liquidity over the entire sample period. If the liquidity-adjusted CAPM holds, the intercept will not be significantly different from zero $(\alpha=0)$. The results are similar but more statistically significant than those reported in Table 5. Panels A and B show that both the net beta and the liquidity net beta are positive and significantly priced at the $1 \%$ level ( $t$-values of 2.78 in both cases) providing support to the liquidity-adjusted CAPM. Positive risk premiums imply that stocks with higher sensitivity to aggregate liquidity shocks offer higher expected returns. The net beta is significantly priced even in the case where the effect of market risk is isolated in the cross-sectional regressions (Panel C). Once again it is evident that the liquidity net beta is priced solely due to $\beta_{i t}^{2}$, whereas $\beta_{i t}^{3}$ and $\beta_{i t}^{4}$ are not priced (Panel D). All coefficients have the expected sign according to the liquidity-adjusted CAPM predictions, except the one corresponding to $\beta_{i t}^{4}$. The average adjusted $R^{2}$ values are larger than those of Table 5. 
Expected liquidity $E\left(c_{t}\right)$ is not priced in any case, a finding that rejects the liquidity-adjusted CAPM. It is also presented in the model with a negative sign. This finding, based on liquidity as a characteristic, is also reported by Eleswarapu and Reinganum (1993), Brennan and Subrahmanyam (1996) and Rubio and Tapia (1998) who employ US and Spanish relative bid-ask spread measures, confirming the idea that asset returns are a decreasing function of liquidity since investors have to be compensated for the larger costs they bear in less liquid markets. However, it is inconsistent with the evidence provided by Amihud and Mendelson $(1986,1989)$ who find a strong and positive relationship between liquidity and asset returns. The modelimplied restriction that $\alpha=0$ is not rejected at conventional levels of significance, providing support to the model.

Therefore, using liquidity both as a characteristic and as a risk factor in the Greek market, certain assumptions of the liquidity-adjusted CAPM are rejected, nevertheless it is evident that liquidity risk is strongly priced, mainly arising from the covariation of individual liquidity with local market liquidity. The level of liquidity does not seem to be a relevant variable in our asset pricing tests. Our results suggest that the effects of liquidity level and liquidity risk are separate, and can affect asset prices via different channels. It is also emphasized that asset pricing and liquidity cannot be analyzed in isolation from each other.

\section{Conclusions}

A new non-parametric method for estimating liquidity betas from a high-frequency data set is proposed which builds on realized covariance and realized volatility theory. In contrast to previous work on time-varying betas, the proposed approach is straightforward to implement and has the advantage of not relying on any instruments to 
capture the time variation in the betas, since the latter are directly estimated from returns. Working under a liquidity-adjusted CAPM framework we provide evidence that liquidity risk is strongly priced in the Greek stock market, due to commonality in liquidity and that the level of liquidity is not an important determinant of asset value.

These results support the notion that variation in liquidity is not completely idiosyncratic and cannot be eliminated at a market-wide level. Important insights on portfolio diversification strategies can also be drawn from the findings of this paper, as liquidity can affect asset prices through channels totally independent of traditional market risk. As a direction for future research, liquidity risk could be empirically estimated by using a variety of different microstructure-based liquidity measures in an effort to better understand the relation between asset pricing and liquidity. We hope that our findings will motivate new research with a more comprehensive database. 


\section{References}

Acharya, V., Pedersen, L.H., 2005. Asset pricing with liquidity risk. Journal of Financial Economics 77, 375-410

Allen, F., Carletti, E., 2008. The role of liquidity in financial crises. In Maintaining Stability in a Changing Financial System, Jackson Hole Conference Proceedings, Federal Reserve Bank of Kansas City, 379-412

Amihud, Y., 2002. Illiquidity and stock returns: cross-section and time-series effects. Journal of Financial Markets 5, 31-56

Amihud, Y., Mendelson, H., 1986. Asset pricing and the bid-ask spread. Journal of Financial Economics 17, 223-249

Amihud, Y., Mendelson, H., 1989. The effects of beta, bid-ask spread, residual risk, and size on stock returns. Journal of Finance 44, 479-486

Andersen, T.G., Bollerslev, T., 1997. Intraday periodicity and volatility persistence in financial markets. Journal of Empirical Finance 4, 115-158

Andersen, T.G., Bollerslev, T., 1998. Answering the skeptics: yes, standard volatility models do provide accurate forecasts. International Economic Review 39, 885-905

Andersen, T.G., Bollerslev, T., Diebold, F.X., Ebens, H., 2001a. The distribution of realized stock return volatility. Journal of Financial Economics 61, 43-76 
Andersen, T.G., Bollerslev, T., Diebold, F.X., Labys, P., 2001b. The distribution of realized exchange rate volatility. Journal of the American Statistical Association 96, 42-55

Andersen, T.G., Bollerslev, T., Diebold, F.X., Wu, J., 2004. Analysis of monthly realized beta based on high-frequency intraday data. Unpublished results, Draft Appendix to: Realized Beta: Persistence and Predictability

Andersen, T.G., Bollerslev, T., Diebold, F.X., Wu, J., 2006. Realized Beta: Persistence and Predictability. Advances in Econometrics: Econometric Analysis of Economic and Financial Time Series in Honor of R.F.Engle, and C.W.J. Granger, Volume B: 1-40

Andersen, T.G., Bollerslev, T., Meddahi, N., 2005. Correcting the errors: volatility forecast evaluation using high-frequency data and realized volatilities. Econometrica 73, 279-296

Asparouhova, E., Bessembinder, H., Kalcheva, I., 2010. Liquidity biases in asset pricing tests. Journal of Financial Economics 96, 215-237

Bali, T.G., Cakici, N., Tang, Y., 2009. The conditional beta and the cross-section of expected returns. Financial Management 38, 103-137

Bandi, F.M., Russell, J.R., 2006. Separating microstructure noise from volatility. Journal of Financial Economics 79, 655-692

Barndorff-Nielsen, O.E., Shephard, N., 2004. Econometric analysis of realized covariation: high frequency based covariance, regression, and correlation in financial economics.

Econometrica 72, 885-925 
Bekaert, G., Harvey, C.R., Lundblad, C., 2007. Liquidity and expected returns: lessons from emerging markets. Review of Financial Studies 20, 1783-1831

Bollen, N.P.B., Smith, T., Whaley, R.E., 2004. Modeling the bid/ask spread: measuring the inventory-holding premium. Journal of Financial Economics 72, 97-141

Bollerslev, T., Zhang, B.Y.B., 2003. Measuring and modeling systematic risk in factor pricing models using high-frequency data. Journal of Empirical Finance 10, 533-558

Brennan, M.J., Subrahmanyam, A., 1996. Market microstructure and asset pricing: on the compensation for iliquidity in stock returns. Journal of Financial Economics 41, 441-464

Chordia, T., Roll, R., Subrahmanyam, A., 2000. Commonality in liquidity. Journal of Financial Economics 56, 3-28

Dacorogna, M.M., Gencay, R., Muller, U., Olsen, R.B., Pictet, O.V., 2001. An Introduction to High-Frequency Finance. Academic Press

Dunne, P.G., Moore, M.J., Papavassiliou, V.G., 2011. Commonality in returns, order flows and liquidity in the Greek stock market. European Journal of Finance 17, 577-587

Ebens, H., 1999. Realized stock volatility. Unpublished results, John Hopkins University

Eleswarapu, V., Reinganum, M., 1993. The seasonal behavior of liquidity premium in asset pricing. Journal of Financial Economics 34, 373-386

Fama, E.F., French, K.R., 1992. The cross-section of expected stock returns. Journal of Finance 47, 427-465 
Fama, E.F., McBeth, J.D., 1973. Risk, return, and equilibrium: empirical tests. Journal of Political Economy 71, 607-636

Geweke, J., S.Porter-Hudak., 1983. The estimation and application of long memory time series. Journal of Time Series Analysis 4, 221-238

Glosten, L., 1994. Is the electronic open limit order book inevitable? Journal of Finance 49, $1127-61$

Handa, P., R. Schwartz, A. Tiwari., 1998. The ecology of an order-driven market. Journal of Portfolio Management 24, 47-55

Hasbrouck, J., Seppi, D.J., 2001. Common factors in prices, order flows and liquidity. Journal of Financial Economics 59, 383-411

Hendershott, T., Moulton, P.C., 2011. Automation, speed, and stock market quality: the NYSE's hybrid. Journal of Financial Markets 14, 568-604

Huberman, G., Halka, D., 2001. Systematic liquidity. Journal of Financial Research 24, 161178

Lee, K-H., 2011. The world price of liquidity risk. Journal of Financial Economics 99, 136161

Liang, S.X., Wei, J.K.C., 2012. Liquidity risk and stock returns around the world. Journal of Banking and Finance, in press

Liu, W., 2006. A liquidity-augmented capital asset pricing model. Journal of Financial Economics 82, 631-671 
Martinez, M.A., Nieto, B., Rubio, G., Tapia, M., 2005. Asset pricing and systematic liquidity risk: an empirical investigation of the Spanish stock market. International Review of

Economics and Finance 14, 81-103

Newey, W., West, K., 1987. A simple heteroskedasticity and autocorrelation consistent covariance matrix. Econometrica 55, 703-708

Parlour, C., Seppi, D., 2008. Limit order markets: a survey. Handbook of Financial Intermediation \& Banking A.W.A. Boot and A. V. Thakor eds.

Pastor, L., Stambaugh, R.F., 2003. Liquidity risk and expected stock returns. Journal of Political Economy 111, 642-685

Protter, P., 2004. Stochastic Integration and Differential Equations. New York: SpringerVerlag

Rouwenhorst, K.G., 1999. Local return factors and turnover in emerging stock markets. Journal of Finance 54, 1439-1464

Rubio, G., Tapia, M., 1998. The liquidity premium in equity pricing under a continuous auction system. European Journal of Finance 4, 1-28

Sadka, R., 2006. Momentum and post-earnings announcement drift anomalies: the role of liquidity risk. Journal of Financial Economics 80, 309-349

Scholes, M., Williams, J., 1977. Estimating betas from nonsynchronous data. Journal of Financial Economics 5, 341-360 
Taylor, S.J., 2005. Asset Price Dynamics, Volatility, and Prediction. Princeton University Press

Vagianos, D., 2004. Flight to quality, flight to liquidity, and the pricing of risk. Working paper, London School of Economics

Vaihekoski, M., 2009. Pricing of liquidity risk: empirical evidence from Finland. Applied Financial economics 19, 1547-1557

Veronesi, P., 1999. Stock market overreaction to bad news in good times: a rational expectations equilibrium model. Review of Financial Studies 12, 975-1007

Watanabe, A., Watanabe, M., 2008. Time-varying liquidity risk and the cross section of stock returns. Review of Financial Studies 21, 2449-2486 


\section{Table 1: Unconditional daily volatility distributions}

The table summarizes the distributions of the raw daily volatilities for the six most heavily traded stocks of the FTSE/ATHEX20 index. The mean, standard deviation, skewness, kurtosis, and Jarque-Bera test statistics are reported. P-values are shown in parentheses. Panel A depicts the realized daily variances $\left(\hat{\sigma}_{t}^{2}\right)$, Panel B depicts the realized daily S.D. $\left(\hat{\sigma}_{t}\right)$, and Panel $\mathrm{C}$ summarizes the distributional properties of the realized logarithmic standard deviations $\left(\log \left(\hat{\sigma}_{t}\right)\right)$. All three volatility measures are calculated from 5-minute squared intraday returns. The period spans from September 23, 2003 through March 31, 2006, for a total of 635 observations.

\begin{tabular}{|c|c|c|c|c|c|}
\hline Stock & Mean & S.D. & Skew. & Kurt. & J.B. \\
\hline \multicolumn{6}{|c|}{ Panel A: Realized daily variances $\left(\hat{\sigma}_{t}^{2}\right)$} \\
\hline$A L P H A$ & 0.0002 & 0.0002 & 3.997 & 28.670 & $\begin{array}{c}19125.96 \\
(0.000)\end{array}$ \\
\hline ETE & 0.0002 & 0.0002 & 3.154 & 19.098 & $\begin{array}{c}7909.44 \\
(0.000)\end{array}$ \\
\hline$E U R O B$ & 0.0002 & 0.0002 & 6.163 & 71.922 & $\begin{array}{c}129703.90 \\
(0.000)\end{array}$ \\
\hline HTO & 0.0002 & 0.0002 & 2.379 & 11.255 & $\begin{array}{c}2401.64 \\
(0.000)\end{array}$ \\
\hline$P P C$ & 0.0002 & 0.001 & 21.998 & 514.797 & $\begin{array}{c}6981607.00 \\
(0.000)\end{array}$ \\
\hline TPEIR & 0.0003 & 0.0004 & 10.868 & 180.217 & $\begin{array}{c}843446.60 \\
(0.000) \\
\end{array}$ \\
\hline \multicolumn{6}{|c|}{ Panel B: Realized daily S.D. $\left(\hat{\sigma}_{t}\right)$} \\
\hline$A L P H A$ & 0.013 & 0.005 & 1.603 & 7.842 & $\begin{array}{l}892.34 \\
(0.000)\end{array}$ \\
\hline ETE & 0.013 & 0.005 & 1.374 & 6.168 & $\begin{array}{l}465.25 \\
(0.000)\end{array}$ \\
\hline EUROB & 0.012 & 0.005 & 2.007 & 11.255 & $\begin{array}{l}2229.21 \\
(0.000)\end{array}$ \\
\hline HTO & 0.014 & 0.005 & 1.115 & 4.788 & $\begin{array}{l}216.26 \\
(0.000)\end{array}$ \\
\hline$P P C$ & 0.012 & 0.008 & 11.047 & 186.263 & $\begin{array}{c}901530.80 \\
(0.000)\end{array}$ \\
\hline TPEIR & 0.015 & 0.007 & 3.201 & 24.501 & $\begin{array}{c}13316.06 \\
(0.000) \\
\end{array}$ \\
\hline \multicolumn{6}{|c|}{ Panel C: Realized logarithmic SD $\left(\log \left(\hat{\sigma}_{t}\right)\right)$} \\
\hline$A L P H A$ & -4.426 & 0.370 & 0.174 & 3.158 & $\begin{array}{c}3.86 \\
(0.000)\end{array}$ \\
\hline ETE & -4.417 & 0.363 & 0.125 & 3.107 & $\begin{array}{l}1.96 \\
(0.000)\end{array}$ \\
\hline EUROB & -4.472 & 0.389 & 0.310 & 3.262 & $\begin{array}{l}11.98 \\
(0.002)\end{array}$ \\
\hline HTO & -4.334 & 0.341 & 0.102 & 2.874 & $\begin{array}{c}1.517 \\
(0.068)\end{array}$ \\
\hline$P P C$ & -4.522 & 0.412 & 0.575 & 6.460 & $\begin{array}{l}351.79 \\
(0.000)\end{array}$ \\
\hline TPEIR & -4.275 & 0.376 & 0.610 & 4.184 & $\begin{array}{c}76.52 \\
(0.000) \\
\end{array}$ \\
\hline
\end{tabular}




\section{Table 2: Conditional distribution of stock market volatility}

The table depicts the time-series dependence of the realized logarithmic standard deviations computed for the six most heavily traded stocks of the FTSE/ATHEX20 index. It shows the Ljung-Box portmanteau test for up to the $22^{\text {nd }}$ order $\left(\mathrm{Q}_{22}\right)$ along with the corresponding $\mathrm{p}$ values shown in brackets, the augmented Dickey-Fuller unit root test (ADF) employing the Schwarz information criterion (SIC), and finally the Geweke-Porter-Hudak (GPH) estimate for the degree of fractional integration $\left(\mathrm{d}_{\mathrm{GPH}}\right)$, using $\theta=0.5$ and $\theta=0.8$. OLS standard errors are given in parentheses. The period spans from September 23, 2003 through March 31, 2006, for a total of 635 observations.

\begin{tabular}{lcccc}
\hline Stock & $\mathrm{Q}_{22}$ & $\mathrm{ADF}(\mathrm{SIC})$ & $\mathrm{d}_{\mathrm{GPH}(0.5)}$ & $\mathrm{d}_{\mathrm{GPH}(0.8)}$ \\
\hline ALPHA & 606.93 & $-8.326^{*}$ & 0.168 & $0.151^{*}$ \\
& {$[0.000]$} & & $(0.125)$ & $(0.054)$ \\
ETE & 710.88 & $-5.350^{*}$ & $0.375^{* *}$ & $0.119^{* *}$ \\
& $[0.000)]$ & & $(0.176)$ & $(0.049)$ \\
EUROB & 1069.5 & $-5.798^{*}$ & $0.403^{* *}$ & $0.109^{* *}$ \\
& {$[0.000]$} & & $(0.182)$ & $(0.051)$ \\
HTO & 535.69 & $-11.511^{*}$ & 0.226 & $0.112^{* *}$ \\
& {$[0.000]$} & & $(0.157)$ & $(0.045)$ \\
PPC & 808.45 & $-8.979^{*}$ & 0.217 & $0.154^{*}$ \\
& {$[0.000]$} & & $(0.142)$ & $(0.050)$ \\
TPEIR & 1096.0 & $-5.140^{*}$ & $0.329^{* *}$ & $0.138^{*}$ \\
& {$[0.000]$} & & $(0.138)$ & $(0.053)$ \\
\hline
\end{tabular}

Notes: MacKinnon (1996) critical values: -3.440 at the $1 \%$ level; -2.865 at the $5 \%$ level; 2.569 at the $10 \%$ level

$*$, and ${ }^{* *}$ superscripts denote significance at the $1 \%$ and $5 \%$ levels, respectively 


\section{Table 3: Dynamics of daily realized betas and covariances}

The table shows the mean, the standard deviation, the augmented-Dickey-Fuller unit root test (ADF) employing the Schwarz information criterion (SIC), the Ljung-Box portmanteau statistic for up to twelfth-order autocorrelation and the Geweke-Porter-Hudak (GPH) estimates for the degree of fractional integration using $\theta=0.5$ for the daily realized betas. Pvalues are shown in brackets and OLS standard errors are reported in parentheses. Rows 6 and 8 of the table report the Ljung-Box portmanteau statistic and the degree of fractional integration of the daily realized covariances, respectively. The period spans from September 23, 2003 through March 31, 2006, for a total of 635 observations. Daily realized betas and covariances are calculated from 5-minute returns.

\begin{tabular}{ccccccc}
\hline & ALPHA & ETE & EUROB & HTO & PPC & TPEIR \\
\hline Mean & 1.14 & 1.23 & 0.97 & 0.98 & 0.61 & 1.03 \\
S.D. & 0.68 & 0.69 & 0.71 & 0.70 & 0.58 & 0.74 \\
ADF(SIC) & $-22.79^{*}$ & $-21.79^{*}$ & $-9.05^{*}$ & $-22.50^{*}$ & $-21.92^{*}$ & $-10.44^{*}$ \\
Q(12) & 33.00 & 26.99 & 103.67 & 24.52 & 23.43 & 136.21 \\
& {$[0.000]$} & {$[0.000]$} & {$[0.000]$} & {$[0.000]$} & {$[0.000]$} & {$[0.000]$} \\
Q(12)cov & 379.46 & 469.35 & 414.28 & 432.85 & 125.46 & 514.01 \\
& {$[0.000]$} & {$[0.000]$} & {$[0.000]$} & {$[0.000]$} & {$[0.000]$} & {$[0.000]$} \\
$\mathrm{d}_{\text {GPH }}$ & $0.155^{*}$ & $0.177^{*}$ & $0.150^{*}$ & $0.165^{*}$ & $0.095^{* * *}$ & $0.179^{*}$ \\
& $(0.053)$ & $(0.055)$ & $(0.051)$ & $(0.051)$ & $(0.050)$ & $(0.051)$ \\
$\mathrm{d}_{\text {GPH cov }}$ & $0.389^{*}$ & $0.314^{*}$ & $0.361^{*}$ & $0.369^{*}$ & $0.140^{* *}$ & $0.400^{*}$ \\
& $(0.056)$ & $(0.047)$ & $(0.051)$ & $(0.051)$ & $(0.060)$ & $(0.052)$ \\
\hline
\end{tabular}

Notes: MacKinnon (1996) critical values: -3.440 at the $1 \%$ level; -2.865 at the $5 \%$ level; 2.569 at the $10 \%$ level

$*, * *$, and $* * *$ superscripts denote significance at the $1 \%, 5 \%$, and $10 \%$ levels, respectively 


\section{Table 4: Statistics for daily liquidity betas}

The table (Panel A) shows the liquidity beta estimates (mean values) constructed from 5minute individual stock and market returns and individual stock and market liquidity innovations. The results from the augmented-Dickey-Fuller (ADF) unit root test using the Schwarz Information Criterion (SIC) are reported in Panel B. The period spans from September 23, 2003 through March 31, 2006, for a total of 635 observations.

\begin{tabular}{llccccc}
\hline & \multicolumn{3}{c}{ Panel A } & \multicolumn{3}{c}{ Panel B } \\
\hline Stock & $\beta_{i t}^{2}$ & $\beta_{i t}^{3}$ & $\beta_{i t}^{4}$ & $A D F\left(\beta_{i t}^{2}\right)$ & $A D F\left(\beta_{i t}^{3}\right)$ & $A D F\left(\beta_{i t}^{4}\right)$ \\
\hline ALPHA & 0.58 & 0.40 & -0.49 & $-24.26^{*}$ & $-24.79^{*}$ & $-23.97^{*}$ \\
ETE & 0.27 & 0.26 & -0.17 & $-18.46^{*}$ & $-23.72^{*}$ & $-24.24^{*}$ \\
EUROB & 0.42 & -0.26 & -0.12 & $-4.70^{*}$ & $-16.33^{*}$ & $-27.19^{*}$ \\
HTO & 0.40 & -0.08 & -0.11 & $-24.09^{*}$ & $-25.88^{*}$ & $-25.67^{*}$ \\
PPC & 0.30 & 1.02 & -0.26 & $-3.74^{*}$ & $-23.74^{*}$ & $-27.05^{*}$ \\
TPEIR & 0.68 & 0.35 & -0.28 & $-24.40^{*}$ & $-24.94^{*}$ & $-11.47^{*}$ \\
\hline
\end{tabular}

Notes: MacKinnon (1996) critical values: -3.440 at the $1 \%$ level; -2.865 at the $5 \%$ level; 2.569 at the $10 \%$ level

* superscript denotes significance at the $1 \%$ level 


\section{Table 5: Fama and MacBeth cross-sectional regressions}

The table reports the time-series averages of estimated risk premia from the Fama and MacBeth cross-sectional regressions on the liquidity-adjusted CAPM. The $t$-statistics reported in parentheses are estimated using the Newey and West (1987) method using 4 lags. Liquidity betas are constructed using innovations in liquidity obtained from an autoregressive (AR) model. Panel A shows the regression results using the net beta as the only regressor, whereas Panel B depicts the estimated premia from the regressions where the liquidity net beta is employed as the sole regressor. Panel C depicts the results where the standard market beta's influence on the stock returns is isolated from the net beta's effect, and finally Panel D examines each liquidity risk separately. The last column reports the average adjusted $R^{2}$. The period spans from September 2003 through March 2006, for a total of 635 trading days. The total number of observations in the cross-sectional series is 3,810 .

\begin{tabular}{|c|c|c|c|c|c|}
\hline Panel A & & 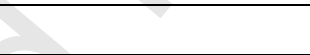 & & & \\
\hline Intercept & $\beta_{i t}^{6}$ & & & & Adjusted- $R^{2}$ \\
\hline$-0.0001(-0.27)$ & $0.000003(2.19)^{* * *}$ & 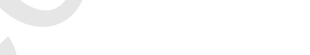 & & & 0.05 \\
\hline Panel B & 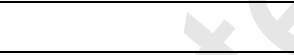 & 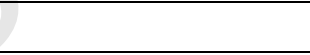 & & & \\
\hline Intercept & $\beta_{i t}^{5}$ & & & & \\
\hline$-0.0001(-0.26)$ & $0.000003(2.19)^{* *}$ & & & & 0.05 \\
\hline Panel C & 8 & & & & \\
\hline Intercept & $\beta_{i t}^{1}$ & $\beta_{i t}^{6}$ & & & \\
\hline$-0.0002(-0.35)$ & $0.0003(0.27)$ & $0.000003(1.89)^{* * *}$ & & & 0.07 \\
\hline Panel D & W & & & & \\
\hline Intercept & $\beta_{i t}^{1}$ & $\beta_{i t}^{2}$ & $\beta_{i t}^{3}$ & $\beta_{i t}^{4}$ & \\
\hline $0.002(0.81)$ & $0.0003(0.27)$ & $0.000004(2.13)^{* *}$ & $-0.00001(-0.35)$ & $0.00006(0.96)$ & 0.10 \\
\hline
\end{tabular}

$* * *$ denotes significance at the $10 \%$ level

$* *$ denotes significance at the $5 \%$ level 


\section{Table 6: Fama and MacBeth extended cross-sectional regressions}

The table reports the time-series averages of estimated risk premia from the Fama and MacBeth extended cross-sectional regressions on the liquidity-adjusted CAPM. The $t$-statistics reported in parentheses are estimated using the Newey and West (1987) method using 4 lags. Liquidity betas are constructed using innovations in liquidity obtained from an autoregressive (AR) model. $E(c t)$ denotes the expected liquidity computed as each stock's average liquidity over the entire sample period. Panel A shows the regression results using the net beta and the expected liquidity as the only regressors, whereas Panel B depicts the estimated premia from the regressions where the liquidity net beta replaces the net beta. Panel C depicts the results where the standard market beta's influence on the stock returns is isolated from the net beta's effect, and finally Panel D examines each liquidity risk separately. The last column reports the average adjusted $R^{2}$. The period spans from September 2003 through March 2006, for a total of 635 trading days. The total number of observations in the crosssectional series is 3,810 .

\begin{tabular}{|c|c|c|c|c|c|c|}
\hline Panel A & & & & & & \\
\hline Intercept & $E\left(c_{t}\right)$ & $\beta_{i t}^{6}$ & & & & Adjusted- $R^{2}$ \\
\hline$-0.0003(-0.89)$ & $-0.05(-0.30)$ & $0.000005(2.78)^{*}$ & & & & 0.08 \\
\hline Panel B & & $x_{n}$ & & & & \\
\hline Intercept & $E\left(c_{t}\right)$ & $\beta_{i t}^{5}$ & & & & \\
\hline$-0.0003(-0.88)$ & $-0.05(-0.30)$ & $0.000005(2.78)^{*}$ & & & & 0.08 \\
\hline \multicolumn{7}{|l|}{ Panel C } \\
\hline Intercept & $E\left(c_{t}\right)$ & $\beta_{i t}^{1}$ & $\beta_{i t}^{6}$ & & & \\
\hline$-0.0004(-0.75)$ & $-0.07(-0.44)$ & $0.0003(0.33)$ & $0.000004(2.40)^{* *}$ & & & 0.10 \\
\hline Panel D & 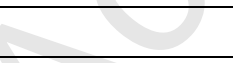 & & & & & \\
\hline Intercept & $E\left(c_{t}\right)$ & $\beta_{i t}^{1}$ & $\beta_{i t}^{2}$ & $\beta_{i t}^{3}$ & $\beta_{i t}^{4}$ & \\
\hline$-0.0005(-0.89)$ & $-0.07(-0.45)$ & $0.0003(0.33)$ & $0.000005(2.58)^{* *}$ & $-0.00001(-0.38)$ & $0.00006(0.92)$ & 0.12 \\
\hline
\end{tabular}

$* *$ denotes significance at the $5 \%$ level

*denotes significance at the $1 \%$ level 